\title{
Dual Ring Loaded Patch with Tri-band Resonance
}

\author{
Varindra Kumar \\ Electrical Engineering \\ University of Cambridge \\ Cambridge, UK \\ Vk318@cam.ac.uk
}

\author{
Abdullah Alzahrani \\ Electrical Engineering \\ University of Cambridge \\ Cambridge, UK \\ Aaka4@cam.ac.uk
}

\begin{abstract}
A patch antenna with its tri-band resonance at $1.8 \mathrm{GHz}, 2.5 \mathrm{GHz}$ and $3.59 \mathrm{GHz}$ has been designed and a method to miniaturize the size using a metamaterial with dual circular ring loaded at its ground layer has been discussed. The reduced size patch with dual circular ring loaded at ground layer provides a resonance similar to its patch with unloaded ground layer while providing similar antenna parametric results for its reflection coefficient, gain, bandwidth and efficiency. The effect of loading the dual circular ring at the ground layer provides a mechanism for size reduction (from the original patch size of $41.5 \mathrm{~mm} \mathrm{x} 31 \mathrm{~mm}$ to $36 \mathrm{~mm} \mathrm{x} 28$ $\mathrm{mm}$ ) in the patch of about $21.64 \%$. The proposed antenna is perfectly suited for its application in wireless media due to its resonance at three frequency band.
\end{abstract}

\section{Keywords-Patch, Antenna, Slot, Ring}

\section{INTRODUCTION}

The next generation technology looks for innovative ways to miniaturise the electronic devices. The Antenna being communication media in these devices is often one of the component with large space and it needs to be miniaturised. At the $\mathrm{GHz}$ frequency range, the patch size is decided by the factor of its transmitting/receiving signal wavelength. With the isolation of patch element with other metallic layers being important for its reliable signal transmission/reception, the real estate of the PCB gets an additional increase. The successful signal communication requires its antenna parameters such as radiation, bandwidth and gain to be significant enough within the intended operating frequency band. This paper talks about a design of low profile flexible microstrip patch antenna working at various operating frequencies such as $1.8 \mathrm{GHz}, 2.5$ $\mathrm{GHz}$ and $3.59 \mathrm{GHz}$ with the use of a thin polyimide substrate $(1.6 \mathrm{~mm})$ and addition of dual ring metamaterial at its ground layer. The loading of metamaterial can resonate the patch at its sub-wavelength [1 - 2] thus reducing the overall patch size with its resonance at similar frequencies. Over the past, the patch miniaturisation has been obtained using traditional techniques with the application of high value substrate material [3 - 5], dielectric loading [6 - 8], shorting pins [9$10]$ and slots $[11-12]$. This paper talks about patch miniaturisation with the addition of dual ring slots at its ground layer. The effect of slot at its ground layer over a traditional patch antenna for its antenna parameters at its resonating frequencies has been evaluated and compared. The full field solver software tool such as CST Microwave studio and Keysight based ADS has been used to model and simulate the design and obtain the result for its various parameters such as reflection coefficient, VSWR, Gain and Efficiency. A comparison of the results has been obtained for patch configurations (Patch antenna loaded with metamaterial at its ground layer and patch antenna without loading metamaterial) using field solver software tools while plots such as permittivity, permeability behaviour, S11 and S12 parametric comparison have been obtained using Matlab.

\section{Design Methodology}

\section{A. CSRR Design}

The application of the metamaterial in patch application is one method to miniaturise its size. Here a dual ring metamaterial has been designed and is shown in Fig. 1. The metamaterial is made of two concentric circular rings with the outer dimension of the ring being $7.1 \mathrm{~mm}$, the width of the ring being $0.8 \mathrm{~mm}$ while the spacing between two rings is 0.5 $\mathrm{mm}$ and its thickness is $0.001 \mathrm{~mm}$. The rings are designed using copper and is laid over a $7.5 \mathrm{~mm} \times 7.5 \mathrm{~mm} \times 1.6 \mathrm{~mm}$ polyimide substrate (dielectric constant of 3.5 and tangent loss of 0.0027$)$.

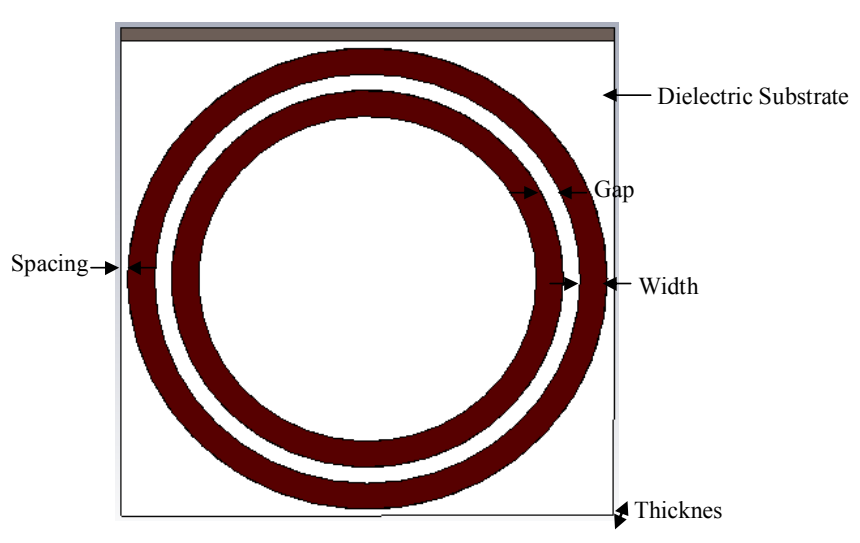

Fig. 1 Dual ring patch

To characterize the metamaterial behavior, its S11 and S12 parameters have been obtained and is shown in Fig. 2. The analytical functions [13 - 14] have been used to find the effective permittivity and permeability with its reflection and transmission parameters using Matlab and is shown in Fig. 3. Here $\varepsilon$ and $\mu$ represent the permittivity and permeability of the designed structure. As shown here the relative permittivity and permeability is negative within the intended frequency range, 
thus the metamaterial behaves as Double Negative (DNG) metamaterial structure.

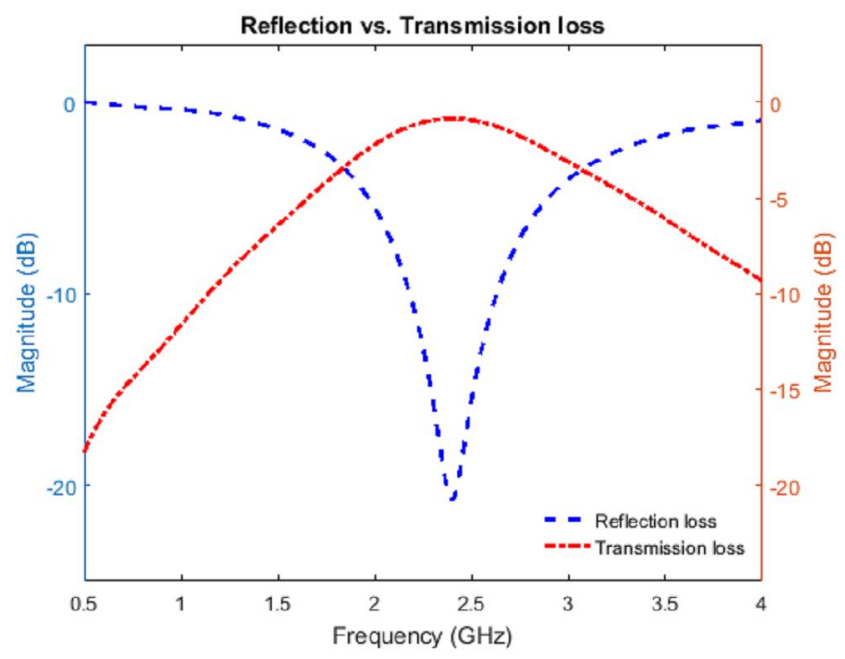

Fig. 2 S11 and S12 parameter for dual ring

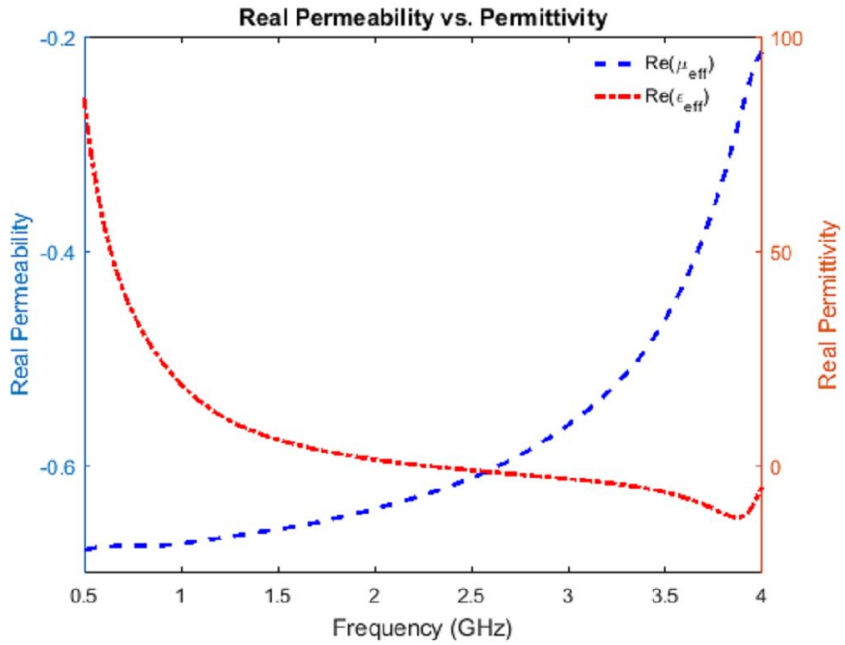

Fig. 3 Real Permeability and permittivity plot for dual ring

\section{B. Patch Antenna Design}

A patch antenna with its resonance at three different frequency, $1.8 \mathrm{GHz}, 2.5 \mathrm{GHz}$ and $3.59 \mathrm{GHz}$ has been designed and simulated. The patch has been miniaturized with the loading of dual circular ring metamaterial as its slot at its ground layer. Figs. 4 and 5 show the top view of the original and miniaturized patch antenna designed using CST/ADS software. The original patch is designed using copper conductive media and has a dimension of $41.5 \mathrm{~mm} \times 31 \mathrm{~mm} \times$ $0.01 \mathrm{~mm}$ while it is laid over $1.6 \mathrm{~mm}$ thick polyimide substrate with dielectric constant of 3.5 and tangent loss of 0.0027 . The ground layer is made of PEC media with thickness $0.01 \mathrm{~mm}$. The conducting patch is connected through a copper feed of $23.6 \mathrm{~mm} \times 2.0 \mathrm{~mm} \times 0.001 \mathrm{~mm}$. Similarly the miniaturized patch is designed with copper conductive media and have a dimension of $36 \mathrm{~mm} \times 28 \mathrm{~mm} \times 0.01 \mathrm{~mm}$ while it is laid over
$1.6 \mathrm{~mm}$ thick polyimide substrate with dielectric constant of 3.5 and tangent loss of 0.0027 . The ground layer is made of PEC media with thickness $0.01 \mathrm{~mm}$. The conducting patch is connected through a copper feed of $19 \mathrm{~mm} \times 2 \mathrm{~mm} \times 0.001$ $\mathrm{mm}$. A dual ring slot with the dimension as described in the previous section has been designed at its ground layer and is placed at $(-1 \mathrm{~mm},-2 \mathrm{~mm})$ from the centre of the patch.

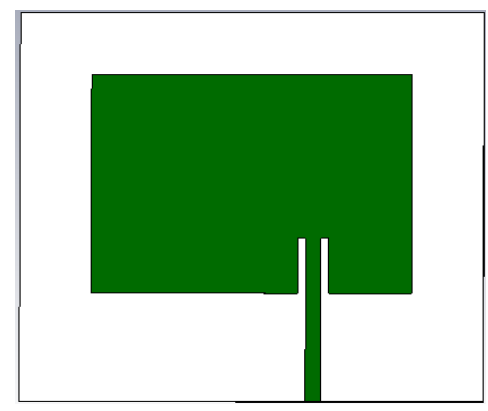

Fig. 4 Patch antenna without dual ring loading

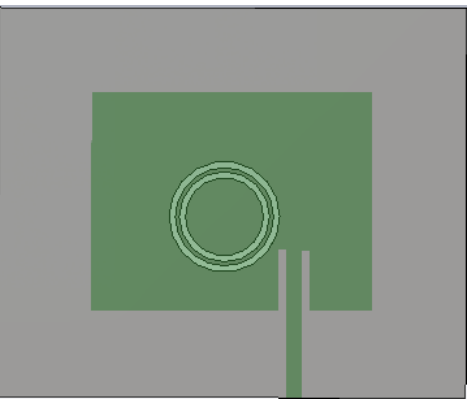

Fig. 5 Patch antenna with dual ring loading at ground layer

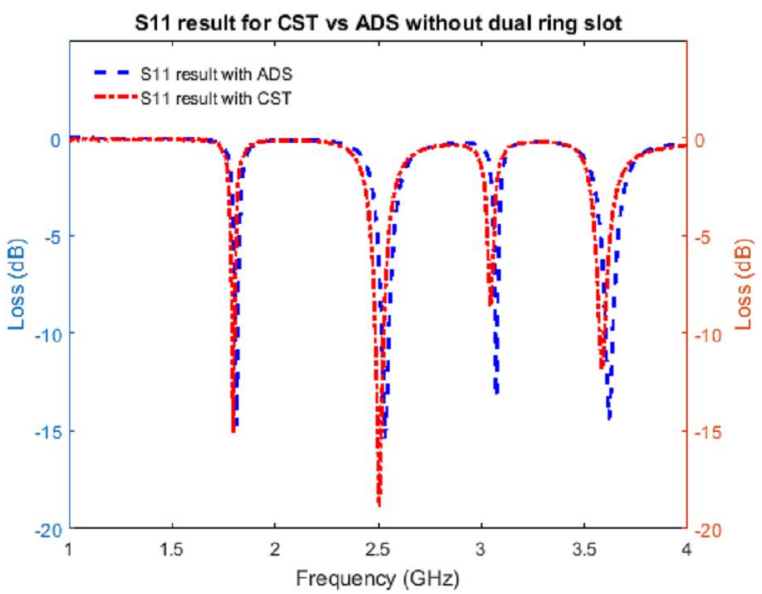

Fig. 6 Comparison of S11 parameter without dual ring slot

Fig. 6 shows a comparison of the S11 parameter for the patch without loading the dual ring structure while Fig. 8 shows a comparison of the S11 parameter for the patch with loading the metamaterial at its ground layer. As shown here the resonating frequencies for the patch loaded with metamaterial matches with the patch without loading the metamaterial for ADS and CST software simulated results while providing a similar reflection coefficient. 


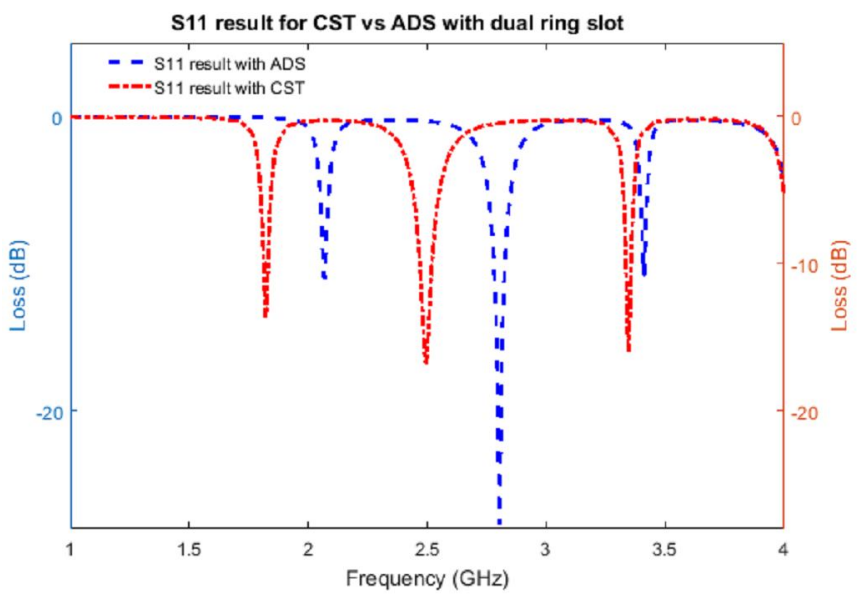

Fig. 7 Comparison of S11 parameter with dual ring slot at ground layer

Figs 6 and 7 shows some shift in resonance frequencies with the band at $2.0 \mathrm{GHz}, 2.8 \mathrm{GHz}$ and $3.4 \mathrm{GHz}$ for the results obtained through ADS software in comparison of CST software obtained results at $1.82 \mathrm{GHz}, 2.5 \mathrm{GHz}$ and $3.35 \mathrm{GHz}$ for the dual ring loaded patch element.

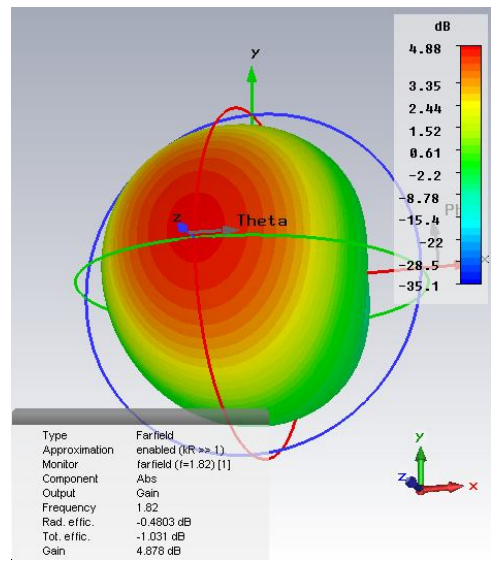

Fig. 8 Radiation pattern at $1.82 \mathrm{GHz}$

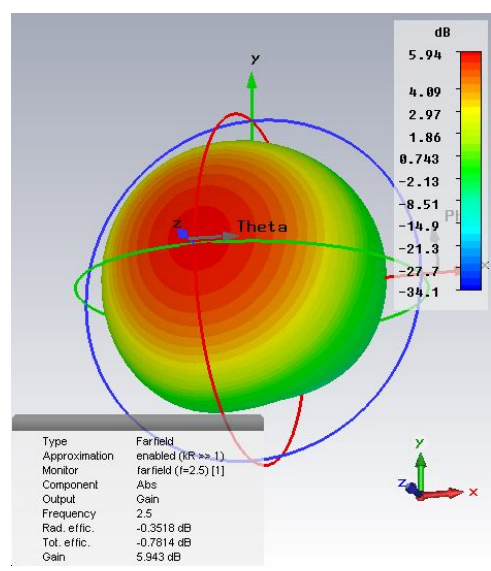

Fig. 9 Radiation pattern at $2.5 \mathrm{GHz}$

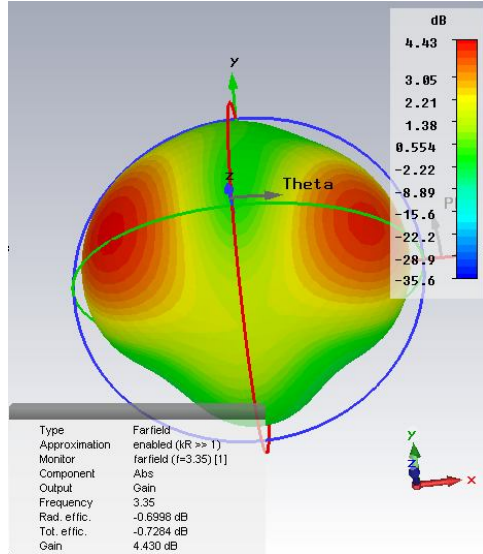

Fig. 10 Radiation pattern at $3.35 \mathrm{GHz}$

The radiation pattern of the patch with dual ring slot at its resonating frequencies has been obtained and shown in Figs. 8-10.

\section{COMPARISON OF PARAMETRS}

Table I shows a parametric comparison of the patch for its reflection coefficient, VSWR, Gain, Directivity and Efficiency with and without slot at the ground layer obtained through CST and ADS software. The results obtained through two software shows some difference in its patch resonance, however with the introduction of dual ring slot in its ground layer there is a reduction in the patch dimension while resonating at similar frequencies to its unloaded patch. The gain and directivity obtained from these two different software tools are similar while there is a reduction of efficiency obtained through ADS software tool. Table I also shows that CST software provides more accurate results for its gain and efficiency.

TABLE I

COMPARISON OF PATCH ANTENNAS

\begin{tabular}{|c|c|c|c|c|c|}
\hline & & $\begin{array}{c}\text { Freq }\left(f_{o}\right) \\
\text { in } \mathrm{GHz}\end{array}$ & $\mathrm{S} 11(\mathrm{~dB})$ & VSWR & Gain (dB) \\
\hline \multirow{6}{*}{ CST } & \multirow{3}{*}{$\begin{array}{c}\text { Patch } \\
\text { without } \\
\text { MTM }\end{array}$} & 1.8 & -15.03 & 1.43 & 5.31 \\
\hline & & 2.5 & -18.5 & 1.27 & 6.52 \\
\hline & & 3.59 & -11.63 & 1.71 & 5.73 \\
\hline & \multirow{3}{*}{$\begin{array}{c}\text { Patch with } \\
\text { MTM }\end{array}$} & 1.82 & -13.42 & 1.54 & 4.88 \\
\hline & & 2.5 & -16.6 & 1.35 & 5.94 \\
\hline & & 3.35 & -15.86 & 1.38 & 4.43 \\
\hline \multirow{7}{*}{ ADS } & \multirow{4}{*}{$\begin{array}{c}\text { Patch } \\
\text { without } \\
\text { MTM }\end{array}$} & 1.8 & -14.56 & 1.46 & 4.82 \\
\hline & & 2.53 & -15.41 & 1.41 & 6.01 \\
\hline & & 3.0 & -13.3 & 1.55 & 4.37 \\
\hline & & 3.63 & -13.91 & 1.51 & 5.77 \\
\hline & \multirow{3}{*}{$\begin{array}{c}\text { Patch with } \\
\text { MTM }\end{array}$} & 2.0 & -10.71 & 1.82 & 4.94 \\
\hline & & 2.8 & -27.75 & 1.09 & 5.48 \\
\hline & & 3.4 & -10.74 & 1.82 & 4.38 \\
\hline
\end{tabular}




\begin{tabular}{|c|c|c|c|c|c|}
\hline & & $\begin{array}{c}\text { Freq }\left(f_{o}\right) \\
\text { in GHz }\end{array}$ & $\begin{array}{c}\text { Directivity } \\
(\mathrm{dBi})\end{array}$ & $\begin{array}{l}\text { Main Lobe } \\
\text { direction }\left({ }^{\circ}\right)\end{array}$ & $\begin{array}{c}\text { Total } \\
\text { Efficiency } \\
(\%) \\
\end{array}$ \\
\hline \multirow{6}{*}{ CST } & \multirow{3}{*}{$\begin{array}{c}\text { Patch } \\
\text { without } \\
\text { MTM }\end{array}$} & 1.8 & 5.95 & 5 & 86.31 \\
\hline & & 2.5 & 6.78 & 0 & 94.15 \\
\hline & & 3.59 & 6.27 & 38 & 88.48 \\
\hline & \multirow{3}{*}{$\begin{array}{l}\text { Patch with } \\
\text { MTM }\end{array}$} & 1.82 & 5.36 & 4 & 89.53 \\
\hline & & 2.5 & 6.29 & 2 & 92.21 \\
\hline & & 3.35 & 5.13 & 48 & 85.12 \\
\hline \multirow{7}{*}{ ADS } & \multirow{4}{*}{$\begin{array}{c}\text { Patch } \\
\text { without } \\
\text { MTM }\end{array}$} & 1.8 & 6.47 & 0 & 68.34 \\
\hline & & 2.53 & 6.73 & 2 & 84.68 \\
\hline & & 3.0 & 6.33 & 37 & 63.75 \\
\hline & & 3.63 & 7.66 & 60 & 64.65 \\
\hline & \multirow{3}{*}{$\begin{array}{l}\text { Patch with } \\
\text { MTM }\end{array}$} & 2.0 & 6.50 & 0 & 69.83 \\
\hline & & 2.8 & 6.75 & 3 & 74.59 \\
\hline & & 3.4 & 6.68 & 43 & 58.87 \\
\hline
\end{tabular}

\section{CONCLUSION}

The paper talks about modeling a patch antenna for its resonance at $1.8 \mathrm{GHz}, 2.5 \mathrm{GHz}$ and $3.59 \mathrm{GHz}$ and a mechanism to reduce the patch size while providing its resonance at similar frequencies. A comparative study of two different modeling method with the help of CST and ADS software has been obtained for a patch design and its miniaturization using dual circular ring slot at ground layer. The loading of a dual ring slot provides a size reduction (of about $21.64 \%$ ) from the original patch size of $41.5 \mathrm{~mm} \times 31$ $\mathrm{mm}$ to $36 \mathrm{~mm} \times 28 \mathrm{~mm}$. The use of polyimide provides a flexibility in its design for application in medical and consumer electronics.

\section{Acknowledgment}

The author would like to acknowledge the department of Electrical Engineering at University of Cambridge for providing the necessary support and funding for the project.

\section{References}

[1] M. Lapine and S. Tretyakov, "Contemporary notes on metamaterials," IET Microwaves, Antennas \& Propagation, vol. 1, no. 1, pp. 3-11, 2007. DOI: 10.1049/iet-map:20050307
[2] N. Engheta., "An idea for thin sub-wavelength cavity resonator using metamaterials with negative permittivity and permeability," IEEEAntennas Wireless Propag.Lett., vol. 1, no. 1, pp. 1013, 2002. DOI: 10.1109/LAWP.2002.802576

[3] R. Waterhouse, Small microstrip patch antenna. Electronics Letters, pp. 604-605, 1995. DOI: 10.1049/el:19950426

[4] D.H. Schaubert and K.S. Yngvesson, "Experimental study of a microstrip array on high permittivity substrate," IEEE Transactions on Antennas Propagation, vol. 34, pp. 92-97, 1986. doi: 10.1109/TAP.1986.1143723

[5] D.M. Pozar, D.H. Schaubert, Microstrip Antenna. Wiley-IEEE Press, 1995. ISBN: 9780470545270

[6] J. B. Pendry, A.J. Holden, D.J. Robbins, W.J. Stewart, "Low-Frequency Plasmons in Thin Wire Structures," Journal of Physics Condensed Matter, vol. 10, pp. 4785-4809, 1998. DOI: 10.1088/0953$8984 / 10 / 22 / 007$

[7] J.B. Pendry, A.J. Holden, D.J. Robbins, W.J. Stewart, "Magnetism from Conductors and Enhanced Nonlinear Phenomena," IEEE Transactions on Microwave Theory and Techniques, vol. 47, pp. 2075-2084, 1999. DOI: $10.1109 / 22.798002$

[8] A. Mumin, R. Alias, J. Abdullah, S.H. Dahlan, R. Abdulhasan, E.J. Ali, "Simulation of Square Ring Microstrip Patch Antenna Performance Based on Effects of Various Dielectric Substrates," Communications in Computer and Information Science, pp. 679-694, 2017. DOI: 10.1007/978-981-10-6502-6_58

[9] V.G. Veselago, "The Electrodynamics of Substances with Simultaneously Negative Values of $\varepsilon$ and "Soviet Physics Uspekhi, vol. $10, \quad$ pp. 509-514, $1968 . \quad$ DOI: 10.1070/PU1968v010n04ABEH003699

[10] R.B. Waterhouse, S.D. Targonski, D.M. Kokotoff, "Design and performance of small printed antennas," IEEE Transactions on Antennas and Propagation, vol. 46, pp. 1629-1633, 1998. DOI: 10.1109/8.736612

[11] M.I. Sabran, S.K. Abdul Rahim, C.Y. Leow, P.J. Soh, B.W. Chew and G.A.E. Vandenbosch, "Compact circularly polarized truncated square ring slot antenna with suppressed higher resonances," Plos One, vol. 12, no. 2, 2017. DOI: 10.1371 /journal.pone. 0172162

[12] Y. Dong, H. Toyao, T. Itoh, "Design and characterization of miniaturized patch antennas loaded with complementary split-ring resonators," IEEE Transactions on Antennas and Propagation, vol. 60, pp. 772-785, 2012. DOI: 10.1109/TAP.2011.2173120

[13] D.R. Smith, D.C. Vier, T. Koschny and C.M. Soukoulis, "Electromagnetic parameter retrieval from inhomogeneous metamaterials," Phys. Rev. E, vol. 71, no. 3, pp. 36617, 2005. DOI: 10.1103/PhysRevE.71.036617

[14] H. Zhou, "An Improved Method of Determining Permittivity and Permeability by S Parameters," PIERS Process. Beijing, vol. 11, no. 1, pp. 768-773, 2009.

[15] A.G. Jahromi, F. Mohajeri and N. Feiz, "Miniaturization of a rectangular microstrip patch antenna loaded with metamaterial," World academy of Science, engineering and technology, vol. 76, pp. 879-882, 2013. 